\title{
infâncias com as infâncias: narrativas de uma aproximação entre a filosofia e crianças de educação infantil
}

\author{
carmen sanches sampaio ${ }^{1}$ \\ universidade federal do estado do rio de janeiro, brasil \\ josé ricardo santiago ${ }^{2}$ \\ universidade federal do estado do rio de janeiro, brasil \\ renata alves ${ }^{3}$ \\ instituto superior de educação do rio de janeiro, brasil
}

resumo

O que esperar do encontro de adultos e crianças com a potencialidade do ato de filosofar? Que movimentos e possibilidades surgem deste encontro? Que impactos estes movimentos geram em professores que se percebem em constante processo de formação? O presente trabalho busca lançar um olhar sobre estas questões partindo da experiência prática de viver a experiência de filosofar com crianças da Educação Infantil. Através de uma abordagem que complexifica as já naturalizadas relações entre os sujeitos da escola, tempos e saberes, este escrito apresenta um movimento inicial de pensar a articulação práticateoriaprática como um tempo privilegiado de formação docente; denuncia limites e anuncia possibilidades dos modos de fazer escola. As práticas de filosofia com crianças da educação infantil, aqui investigadas, possibilitam pensar para além dos momentos em que convidamos e somos convidados a experienciar o pensamento através de uma aproximação filosófica. O que vamos percebendo, em nossos primeiros movimentos, é que a própria experiência filosófica possibilita pensar a atuação e a formação docente desde outras bases que, muitas vezes, se opõem as práticas majoritariamente valorizadas pela escola. Não são apenas as crianças que lançam perguntas e se aventuram nas possibilidades desta aproximação com elas: os adultos que fazem parte deste diverso grupo que se propõe a filosofar são intimamente atravessados pelas questões que se impõem no movimento de experienciar os pensamentos. $\mathrm{O}$ investimento em uma formação de professores e professoras que se estruture sobre os conceitos de experiência, igualdade das inteligências e a consideração do outro como 'legítimo outro', amplia o horizonte de possibilidades de atuação de docentes comprometidos com uma igualdade que não se apresenta como fim a ser alcançado, mas sim como início de qualquer relação que se proponha emancipadora.

palavras-chave: filosofia com crianças; formação docente; experiência.

\section{infancias con las infancias: narrativas de una aproximación entre la filosofía y niños de educación infantil}

resumen

¿Qué esperar del encuentro entre adultos y niños con el potencial del acto de filosofar? ¿Qué movimientos y posibilidades surgen de este encuentro? ¿Qué impacto generan estos

\footnotetext{
${ }^{1}$ E-mail: carmensanches.unirio@gmail.com

2 E-mail: o_pedagogo@hotmail.com

3 E-mail: nata_alves@hotmail.com
} 
infâncias com as infâncias: narrativas de uma aproximação entre a filosofia e crianças de educação infantil

movimientos en los profesores y profesoras que sienten que están en un constante proceso de formación? Este estudio tiene como objetivo hacer un vistazo a estas cuestiones a partir de la experiencia de filosofar con niños de la educación inicial. A través de un enfoque que trae más complexidad a las relaciones comúnmente naturalizadas entre los sujetos de la escuela, el tiempo y el conocimiento, este escrito tiene un movimiento inicial de pensar la articulación prácticateoriapráctica como un tiempo privilegiado para la formación de maestros y maestras; denuncia los límites y anuncia las posibilidades y formas de hacer escuela. La práctica de filosofía con niños de educación inicial, aquí investigada, permite pensar más allá de los momentos en el que somos invitados a experimentar el pensamiento a través de un enfoque filosófico. Lo que percibimos en nuestros primeros movimientos, es que la experiencia filosófica permite pensar en las actividades y la formación de profesores y profesoras a partir de otras bases que a menudo se oponen a las prácticas escolares usualmente valorizadas por la escuela. No solo son los niños que se entregan a las preguntas y a la aventura de las posibilidades que trae consigo esta aproximación: los adultos que forman parte de este grupo diverso que se propone a filosofar están estrechamente atravesados por cuestiones que se imponen a la circulación de los pensamientos que experimentan. La apuesta en la formación de maestros y maestras que se estructura en los conceptos de la experiencia, la igualdad de las inteligencias y la consideración del otro como "legítimo otro", permite ampliar el horizonte de posibilidades de acción de un docente comprometido con una igualdad que no se presenta como un fin a alcanzar, sino como el comienzo de cualquier relación que se propone emancipadora.

palabras clave: filosofía con niños; formación docente; experiencia.

\section{childhoods with childhoods: narratives of a close relationship between philosophy and preschool children}

abstract

What could be expected from encounters among adults and children that hold a philosophical potential? Which possibilities and movements could emerge from such encounters? Which impacts could these movements generate in teachers that see themselves in constant professional development? This paper aims to shed light on these questions, focusing on the practical experience of living the philosophical act with preschool children. Through an approach which complexifies naturalized relations among school subjects, times and knowledges, this paper presents an initial movement of thinking the practice-theory-practice articulation as a privileged time of teacher development; denounces limits and announces possibilities of ways of doing school.. The philosophical practices with preschool students allow us to think beyond the moments in which we are invited to experience a more philosophical way of thinking. It is noticeable that philosophical experience allows us to think of teaching practices and teacher development in different ways. These approaches are often disregarded by the school as an institution. Not only do children make questions and venture themselves in the possibilities of this approach to philosophy. Adults that are part of this diverse group also engage in philosophy when it comes to experiencing thought. Programs for professional development for teachers which are based on the concept of experience, the notion of the other as an "legitimate one" and equity of intelligences are of utmost importance since it broadens the possibilities of teaching practices that are compromised with equity and it 
does not pose itself as an end to be achieved, but rather as a beginning of any emancipatory relationship.

keywords: philosophy with preschool children; teaching professional development; experience. 
infâncias com as infâncias: narrativas de uma aproximação entre a filosofia e crianças de educação infantil

infâncias com as infâncias: narrativas de uma aproximação entre a filosofia e crianças de educação infantil

\section{introdução}

A relação com as crianças é uma relação de alteridade.

De estranheza. De mistério. De tremor. De perplexidade. De perturbação.

Dependendo do que façamos com tudo isso, a relação terá matizes diversos.

De aproximação amorosa ou de indiferença brutal.

A estranheza pode pulverizar-se até converter-se em pó. Ou o mistério pode ser desvelado, mesmo que saibamos como se reduzem os mistérios a poucas fórmulas do conhecimento.

O tremor é uma sacudida e também é emoção. A perplexidade pode ser reduzida a poucos segundos. Ou durar toda a vida. A perturbação pode importunar, incomodar, ofender. Ou começar a fazer parte de nós mesmos. Carlos Skliar, 2014.

Existem coisas que só se justificam se forem contadas do início...

Paulo Freire diz que a escrita tem seu início antes de se riscar o papel com o grafite do lápis ${ }^{4}$. Como professorxs, nos relacionamos em nosso cotidiano com diversos inícios: o início de uma história, de um livro de literatura infantil, de um ano letivo, de uma relação com as crianças... Este texto busca narrar alguns inícios - e, obviamente, alguns fins, posto que tais inícios não obedecem, de certa maneira, uma ordem cronológica, que coloca a vida e as histórias retas e lineares como uma régua e confere ao início o espaço mais oposto e distante do fim. Arriscamo-nos a dizer que este texto se inicia antes, muito antes do momento em que se digitam estas letras: se inicia com o fim de muitas crenças e valores...

Quando, então, se inicia algo? Em que momento se dá a gênese deste movimento que busca, na filosofia, os movimentos para pensar a prática cotidiana com a Educação Infantil desde outro lugar? Poderíamos dizer que surge no momento mesmo em que dispomos as crianças em roda e iniciamos a leitura de um texto que, para nós, pode dar a pensar?

\footnotetext{
${ }^{4}$ Cf. FREIRE, Paulo. Professora sim, tia não - Cartas a quem ousa ensinar. São Paulo, Cortez, 1995. 
Nos parece incompleto, todavia, apontar este como o nosso ponto de partida, posto que não se parou diante das crianças munidos apenas de um desejo recém-descoberto de filosofar com elas.

Poderíamos então dizer que este é um movimento que se inicia nas possibilidades que surgiram da leitura de reconhecidas teorias acerca da filosofia e da prática filosófica com e para crianças.

Apesar de se aproximar mais do que consideramos ser o início deste movimento que nos estamos propondo a narrar, esta possibilidade limita este início a um tempo muito cronologicamente marcado.

Em nossa língua não é possível desassociar o "quando" que estamos buscando apresentar da palavra "tempo". De que "tempo" estamos falando quando buscamos entender este "quando"?

Para os gregos, a palavra tempo podia ser encontrada de três maneiras distintas: Khrónos, Aión e Kairós.

Aristóteles define khrónos como "[...] o número do movimento segundo o antes e o depois" (Física IV, 220a); O tempo é, nesta concepção, quantidade; há mais ou menos tempo; falta mais ou menos tempo; temos mais ou menos tempo: a totalidade do tempo é a soma do passado e do futuro, sendo o presente um limite entre o que já foi e não é mais (o passado) e o que ainda não foi e, portanto, também não é, mas será (o futuro)" (KOHAN, 2010, p.8).

O tempo khrónos, face mais difundida da complexidade do tempo, nos permitiria localizar precisamente data e hora em que algumas práticas têm início. Aión, por sua vez, possibilita uma movimentação bastante distinta da que é possível estabelecer com o tempo cronológico.

Aión, que designa, já em seus usos mais antigos, a intensidade do tempo
da vida humana, um destino, uma duração, uma temporalidade não
numerável nem sucessiva, mas intensiva e qualitativa (Liddell; Scott,
1966, p.45). Aión é o tempo da experiência e do acontecimento. (KOHAN,
2010, p.8)

Já Kairós, a última face do tempo, traz a potência da oportunidade. Um tempo de estar atento, de abrir-se para o acontecimento. Kairós se apresenta como possibilidade rara de fazer algo acontecer. Potente, no sentido de que apresenta a força do acontecimento, e frágil, uma vez que necessita de um espírito aberto e um 
infâncias com as infâncias: narrativas de uma aproximação entre a filosofia e crianças de educação infantil

corpo sensível a perceber as sutilezas deste acontecimento que, se perdidas, não mais se configurarão da mesma maneira.

Perceber as diferenças presentes nas percepções gregas acerca do tempo, complexificam nossa própria relação com o tempo e com as palavras que se aproximam e se relacionam com ele.

Este tempo não se apresenta, pois, com um único viés: as três percepções constituem os acontecimentos humanos em sua relação com o tempo. Ainda que se façam perceber mais uma característica do que outras, acreditamos que o tempo humano é Kairós, Khrónos e Aión, atravessados, sobrepostos, entrelaçados.

E foi sob esta perspectiva que se iniciou o movimento de filosofar com crianças da Educação Infantil (2 ${ }^{\mathrm{a}}$ etapa), no Colégio de Aplicação do Instituto Superior de Educação do Rio de Janeiro (Cap/ISERJ5): no estabelecimento de uma interação distinta com o tempo; na complexificação de nossa relação com ele; na transposição dos limites impostos pela cronologia do tempo escolar; na percepção de que o tempo de formação se dá sob outra concepção temporal e, por consequência, sob outra forma de relação entre os sujeitos.

\section{TEMPOS DE FORMAÇÃO como professoras e professores de crianças...}

Desde o ano de 2014 um grupo de 14 estudantes, do curso de Pedagogia, vinculadxs ao subprojeto de Pedagogia/Educação Infantil/UNIRIO/CAPES6, investiga e participa de relações pedagógicas e educativas vivenciadas entre grupos de crianças e de adultos - especialmente, é claro, das que surgem das interações entre estes grupos - no sentido de valorar lógicas e saberes infantis

\footnotetext{
${ }^{5}$ Escola da Rede FAETEC (Fundação de Apoio à Escola Técnica) vinculada à Secretaria Estadual de Ciência, Tecnologia e Inovação.

6 O Programa Institucional de Bolsa de Iniciação à Docência (PIBID), oferecido pela CAPES (Coordenação de Aperfeiçoamento de Pessoal de nível Superior) por meio das Universidades brasileiras que trabalham com formação de professores, dedica-se à concessão de bolsas a estudantes de licenciaturas que se fixem na docência durante a sua graduação. Tem como objetivos potencializar: i) a reflexão sobre os contextos micro e macro da escola; ii) a organização do trabalho escolar e aprendizagem dos estudantes da escola pública; iii) a qualificação do curso de licenciatura; iv) incentivar a formação docente de forma articulada à escola pública e v) colaborar no reconhecimento de saberes diversos na escola através do trabalho (com)partilhado com docentes e discentes na perspectiva de um currículo emancipatório. O projeto PIBID da UNIRIO é constituído por 08 subprojetos e envolve cinco cursos de licenciaturas e 13 escolas públicas.
} 
como constitutivos dos currículos experienciados no cotidiano de uma escola pública de Educação Infantil. Uma professora vinculada à universidade e duas, vinculadas à escola de educação infantil, também fazem parte desse grupo, que conta ainda com dois doutorandos - e também professores da educação básica vinculados ao Programa de Pós-Graduação da UNIRIO.

Um grupo diverso: alunxs de graduação no começo de sua vida acadêmica, buscando sua certificação inicial e professoras da educação básica e da universidade que entendem que é no encontro entre as pessoas que a experiência sobretudo a de formação - acontece.

Esta pluralidade ganha matizes ainda mais marcantes se levarmos em consideração que a participação das crianças da educação infantil e as conversas que estabelecemos com elas são fundamentais para a intensidade deste tempo.

Temos, no e com o grupo, investido no diálogo e na conversa entre o vivido na escola e as narrativas - orais e escritas - produzidas pelxs estudantes abrindo possibilidades para estudos e reflexões sobre processos formativos docentes na perspectiva da investigação da própria prática e da experiência. Formar-se professor(a) no cotidiano escolar, compreendendo-o como tempoespaço ${ }^{7}$ privilegiado de formação docente e produção de conhecimentos, no diálogo entre universidade e escola básica é o nosso objetivo maior.

Nos aproximamos, desta forma, a uma série de coletivos que vem pensando e praticando processos de formação docente na perspectiva da investigacão educativa (CONTRERAS DOMINGO; PÉREZ DE LARA FERRÉ, 2010; KOHAN; MASSCHELEIN, 2014) e, portanto, na perspectiva da experiência. Uma aposta de que o vivido e praticado possa nos atravessar, nos interrogar, estremecer nossas certezas de modo que não possamos mais ser como vínhamos sendo. Os caminhos que vamos, juntos, trilhando tem por base processos formativos que se abastecem da força de perguntas simples na forma, mas potentes em seus sentidos:

\footnotetext{
7 Nos grupos de pesquisa e estudos vinculados ao campo dos estudos e pesquisas com os cotidianos temos unido termos, compreendidos pela ciência moderna como polaridades excludentes, no sentido de interrogar a dicotomia clássica que sob esta perspectiva teórica os constitui.
} 
infâncias com as infâncias: narrativas de uma aproximação entre a filosofia e crianças de educação infantil

O que este tempo de formação pode ser? O que este tempo de formação está sendo? Por que este tempo de formação está sendo como está sendo?

Estas três perguntas - que questionam, neste caso, o que estamos chamando de tempos de formação - abrem a possibilidade de reconhecer outras realidades existentes ou por inventar. Formação como exercício do pensamento, como movimento de perguntar, de investigar, desejar, descobrir, criar...

É importante dizer, ainda, que não estamos sós nesta caminhada. Somos nós e também são outros os que se aventuram em uma experiência de formação pautada sob outras bases. Estamos, como grupo, vinculados à Rede de Formação docente: narrativas e experiências (Rede Formad ${ }^{8}$ ) e enquanto rede vinculados a tantas outras...

Nós e outros... Nosotros... Redes que se articulam em torno de uma formação docente (e humana?) horizontal, não autoritária e democrática.

Formar-se professora e professor de crianças no encontro com o outro crianças e professoras - e no diálogo consigo mesmo. No exercício cotidiano de conversar abrir-se à escuta, deixar-se interpelar, afinar o olhar, a sensibilidade. Interrogar certezas, duvidar, correr riscos. Aprendemos com Simón Rodríguez, apresentado ao nosso grupo por Walter Kohan (2013) que em educação e diríamos, nas ações de formação docente -, se não inventamos, erramos. Um posicionamento radical e potente, que não se conforma com o já sabido e atribui ao não-dado, ao não-estabelecido, ao devir, a potência do fazer pedagógico. Quando, em nossas práticas de formação, nos inspiramos em outras lógicas - incertas, abertas, inventivas - negamos a artificialidade e os limites do que temos. Buscamos, à maneira de Rodriguez, inventar uma formação que se distancie de modos prescritivos, estruturados e estruturantes que tem o como fazer e o que fazer como a priori.

Para nós, a possibilidade de aprender com o que nos acontece, com o que nos interroga, com o que nos surpreende e suspende modos aprendidos de ser,

\footnotetext{
8 Rede formada por diferentes grupos e coletivos docentes e que se articula a outras redes brasileiras e latino-americanas de formação docente (https://sites.google.com/site/redeformad/home).
} 
pensar, aprender, ensinar, dizer, fazer... é abrir-nos à experiência. Não a ideia de experiência como acúmulo de ações vividas, articulada a alguém que tem e acumulou experiências. Mas, sim, como nos fala Contreras Domingo e Nuria Pérez de Lara Ferré,

Es experiencia precisamente porque irrumpe ante lo que era previsto, lo sabido; no puede estar sometida a control, ni ser producto de un plan. Por eso obliga a pensar, para ser acogida en su novedad, como lo que no encaja, o lo que necesita de un nuevo lenguaje, una nueva expression, o un nuevo saber para dar cuenta de ella. Irrumpe también su significado, el sentido de lo vivido. La experiencia lo es en la medida en que reclama significados nuevos para lo vivido [...] Así pues, en ocasiones será la novedad de lo que acontece lo que provoca el sentido de la experiencia, pero en ocasiones será la atribución de un nuevo sentido a lo vivido lo que hará de ello una experiencia. (CONTRERAS DOMINGO; PÉREZ DE LARA FERRÉ, 2010, p. 25).

Em nossas Rodas de Conversa falar e pensar sobre o vivido cotidianamente com as crianças e professoras, representa o desafio de exercitar a circularidade práticateoriaprática. O ponto de partida é a prática. Vamos à teoria para melhor compreender a prática e à prática retornamos para nela intervir, para compreendêla e praticá-la de modos mais favoráveis à aprendizagem, ao ensino e ao processo de formação docente experienciado. Prática compreendida e reconhecida como produção de teoria, teoria em movimento: prática e teoria se reaproximam e retroalimentam-se nesse processo formativo. O desejo e a aposta é que possamos, professorxs e estudantes, vivê-lo como experiência.

\section{NOS ENCONTROS com as crianças...}

Desde abril de 2015, juntamente com o PIBID/UNIRIO de Educação Infantil, temos nos desafiado a filosofar com crianças que têm entre quatro e seis anos de idade, não sob o pretexto de preparar a criança para o estudo da filosofia que se dará no futuro, mas, sim, como possibilidade de experienciar o pensamento com as crianças e, posteriormente, pensar esta experiência. Crianças compreendidas como um "outro legítimo na convivência e na confiança" (MATURANA, 1997).

Pensar na melhor forma de vivenciarmos juntos, adultos e crianças, a potencialidade de filosofar, nos levou a optar por nos encontrarmos, com certa 
infâncias com as infâncias: narrativas de uma aproximação entre a filosofia e crianças de educação infantil

frequência, com uma mesma turma da educação infantil, planejando cada encontro com foco em uma ambientação que seja convidativa à participação, à problematização, à conversa, à conceitualização sem necessariamente se atingir uma verdade, voltando-se, sobretudo, ao exercício do pensamento: viver o desafio de pensar com o outro.

Entendemos esses encontros como possibilidades de estarmos de fato com as crianças, conversando com elas.

Observando e sendo observados por elas.

Escutando e sendo escutados por elas.

Estando atentos ao que elas têm a nos dizer para além da linguagem oral, afetando e sendo afetados por elas, numa relação de horizontalidade onde aprendemos e ensinamos mutuamente, intensificando nossa relação.

Seriam, porém, crianças tão pequenas, capazes de filosofar?

Esta pergunta, todavia, guarda dentro de si outras perguntas:

Qualquer criança pode filosofar?

Somente as crianças grandes?

Também as pequenas?

Se adquire a capacidade de filosofar?

Quando se adquire?

Em que momento da vida?

Recorremos a um texto que ouvimos de Beatriz Fabiana Olarieta ${ }^{9}$ que, ainda que faça uma alusão aos textos e seus sentidos de uma maneira geral, nos permite pensar as relações que podemos estabelecer com as perguntas.

Texto: cebola eterna, capa sobre capa, camadas e camadas de cebola uma sobre a outra.

Ler: Buscar o centro da cebola? Chegar ao coração da cebola?

A cebola não tem coração.

Navegar entre as camadas de cebola.

Não desnudar a cebola (pretender desnudá-la é ela ficar sem nada).

Transitar entre as camadas eternas da cebola. Deslizar-se entre suas lâminas. Abrir-se-passo. Atravessá-las. Enfeitar sua casca dourada.

Deixar o próprio traço no traço.

\footnotetext{
${ }^{9}$ Fragmento de texto produzido no primeiro semestre de 2011 na disciplina ministrada por Walter Omar Kohan intitulada "A coragem da escrita", oferecida pelo Programa de Pós-Graduação em Educação da UERJ.
} 
Neste transitar entre os diversos sentidos de uma pergunta e suas diversas camadas uma questão se impõe:

O que estamos chamando de filosofar?

Filosofia não seria um saber especifico. Mas um tipo de relação ao saber. Algo localizado entre o sujeito que se lança ao saber e ao saber que, simultaneamente, forma e é formado pelo sujeito.

Uma relação ao saber. Um distanciamento que permite questioná-lo.

Outras camadas de perguntas: de que saber estamos falando? Como se estabelecem as interações entre sujeitos e saberes em uma relação que se pretende filosófica?

Que nome dar a este ato de proporcionar perguntas que denunciem os limites do elemento sobre o qual se pergunta e anunciem uma outra possibilidade de organizá-lo, para novamente perceber limites (outros desta vez) e reorganizá-lo, num movimento cíclico de destruição e reconstrução, de morte e vida, de fins e inícios?

El gesto inaugural de la filosofía es aquel en que el pensamiento no se reconoce en el regazo de un saber que ya se tiene, sino en la inquietud de las preguntas; no en el reposo finalmente conseguido del resultado, sino en el movimiento incesante de la aspiración y de la búsqueda; no en la arrogancia triunfante de la posesión sino en la menesterosidad anhelante del deseo. (LARROSA, 2003, p.194).

A inquietude do filósofo seria fruto da potência de um pensamento de natureza filosófica. Pensamento este que não se acomoda diante do que se tem estabelecido. Está em constante movimento e surge de uma ruptura entre um saber que se pensa e o que se pensa sobre determinado saber. Há um espaço do saber do qual se afasta um espaço do pensamento. Não se trata de uma mescla entre ambos e sim de um distanciamento que coloca o pensamento em uma relação ao saber.

Pensar este saber seria um relacionar-se também com o que transborda a ele, com seus limites, pois à medida que pensamos este saber o problematizamos filosoficamente, se apresenta também o que representa um não-saber. Trabalha a filosofia nessa fronteira questionando os limites do que se pode dar a saber; do que pode se saber sobre algo. Larrosa nos aponta ainda: 
infâncias com as infâncias: narrativas de uma aproximação entre a filosofia e crianças de educação infantil

Porque el saber no es sólo un cierto contenido confortablemente aceptado como verdadero sino también, y sobre todo, una determinada delimitación de la frontera entre lo que se sabe, lo que se puede saber y lo que es imposible saber. Y una determinada normativa sobre cómo hay que hacer para saber lo que aún no se sabe. Por eso lo que busca el distanciamiento del filósofo respecto al saber recibido es hacer que el pensamiento sea posible más allá de los límites de lo que se puede y lo que se debe saber, y que el pensar sea posible de un modo otro a como está mandado que hay que saber (LARROSA, 2003, p.197).

Diante destas considerações cabe um retorno às perguntas iniciais.

O que estamos chamando de filosofar?

Seriam, porém, crianças tão pequenas, capazes de filosofar?

Já é dito que por volta dos três, quatro anos de idade, inicia-se a fase dos "Por quês?", fase esta que costuma incomodar muitos adultos, talvez pela possibilidade de não conseguirem ter respostas para muitas das perguntas feitas pelas crianças...

Achamos que vale pensar que o fenômeno que se apresenta nestes casos está para além e para aquém do simples ato de uma criança questionar um adulto em si: trata-se, pois, de uma infância que interroga culturas e relações de poder munida, sobretudo, de sua potência de ver o mundo como se fosse a primeira vez. Suspendendo alguns de seus sentidos e profanando, pois, hábitos e sistemas que docilizam corpos, enquadram pensamentos e formatam subjetividades.

Uma infância para além da cronológica. Uma infância que interrompe a lógica do mundo.

Quando nos colocamos em relação com as crianças e quando juntos, as crianças e nós, nos lançamos na aproximação a um saber, através da filosofia, estamos investindo na infância presente nas crianças e em nós.

Quando uma criança lança uma pergunta acerca dos sentidos das coisas, buscamos, pois nos opor a uma necessidade naturalizada de ter uma resposta exata, de explicar o que é certo ou errado... negando modos de compreender as crianças que as enfraqueçam como sujeitos de conhecimento, privilegiando uma relação que as considere sujeitos em sua potência, que pensam, sentem, agem, e dão sentidos diversos ao que as cerca. 
Quando nos colocamos em relação com as crianças e quando juntos, as crianças e nós, nos lançamos na aproximação a um saber, através da filosofia, estamos investindo na infância presente nas crianças e em nós. A aposta tem sido a de vivermos encontros com as crianças no sentido, como ressalta Kohan (2015, p. 148), de que hacer filosofía supone encontrar una infância en el pensamiento, un punto inicial, un camino para poder pensar.

Em nossa Roda de Conversa onde planejávamos, estudantes e professoras(e)s, nosso primeiro encontro com as crianças, Zé Ricardo ressaltou: $A$ pergunta alimenta o pensamento. Esta fala levou-nos a pensar que apresentar o desenho de um (grande) ponto de interrogação para as crianças seria provocativo para vivermos o movimento de abrir-nos ao pensamento. Levou-nos, sobretudo, ao movimento de pensarmos sobre o perguntar. Cristiane, estudante, ressaltou:

- Acho interessante porque trabalhamos pouco com o perguntar(se) desde pequeno. Saber que você pode perguntar... isso é imprescindível!

Renato, outro estudante, se pergunta, indagando-nos:

- Perguntar e indagar é a mesma coisa? A pergunta não traz em si a expectativa de uma resposta?

Silêncio. Olhares. Dúvida. O que dizer? Como dizer? Vivíamos, entre nós, adultos, o movimento de problematizar o próprio sentido do pensar. Pensar o encontro com as crianças provocava-nos a estarmos juntos e juntos, pensarmos...

No encontro com as crianças, sentados em uma grande roda, iniciamos o primeiro encontro de filosofia com as crianças. Zé, ao mostrar o desenho do ponto de interrogação, pergunta:

- O que é isso?

Imediatamente ouve como resposta:

- É uma pergunta de escritos.

- É um símbolo que pergunta se está bem quando a pessoa está no hospital. Disse uma outra criança, em seguida ${ }^{10}$.

\footnotetext{
10 Soubemos, neste dia, que uma criança, desta turma, estava doente e internada. A turma havia escrito uma carta para essa amiga com algumas perguntas e desenhos.
} 
infâncias com as infâncias: narrativas de uma aproximação entre a filosofia e crianças de educação infantil

Então, José Ricardo afirma:

- Esse é o ponto de interrogação.

E, Ryan, rapidamente exclamou:

- É pra fazê pergunta!

Carmen, então, perguntou:

- Com a voz também se faz pergunta?

Sem pestanejar, João Victor respondeu que sim.

Zé Ricardo diz que tem uma pergunta:

- O que é uma pergunta?

- É difícil? Ryan, respondeu com outra pergunta.

- As perguntas servem pra escrevê, disse Luyza.

- Pra que serve a pergunta? Perguntar é fácil ou é difícil? Indagou Zé Ricardo.

- Difícil... Porque não sabe a pergunta, respondeu Ryan.

Mas, Pérola acrescentou:

- É fácil porque é uma pergunta.

E o Zé indaga:

- Toda pergunta é fácil?

- Sim, responde Pérola.

- Por quê? Zé volta a perguntar.

- Porque sim! Porque sim, sim!! Insiste Pérola.

Silêncio. As crianças, entreolhavam-se...

Então, Zé propôs que as crianças, organizadas em duplas, desenhassem e/ou escrevessem, em papéis diferentes, do jeito que sabiam, duas perguntas: uma fácil e uma difícil. Os papéis eram de cores diferentes. Algumas crianças fizeram desenhos, outras escreveram, do jeito delas. Outras, desenharam e escreveram, como podiam e sabiam. Nós, professoras e estudantes vinculadas ao PIBID/Educação Infantil, sentamo-nos com as crianças acompanhando o processo vivido. Depois, voltamos para a roda, onde as duplas falaram sobre suas perguntas, separando-as, segundo a proposta inicial, em fáceis ou difíceis.

Para algumas crianças pareceu ser difícil pensar uma pergunta, que dirá duas! Ficaram algum tempo olhando para o papel, sem mexer em nada. Outras já 
começaram a desenhar, e quando perguntamos qual era a pergunta, não conseguiam responder ou diziam "não sei". Mas, no movimento de conversar e pensar, as perguntas foram ganhando forma. Na roda, as crianças apresentaram suas perguntas, desenhadas e/ou escritas, para todos. Destacamos algumas:

- Tá tudo bem? Pergunta fácil feita por Pérola.

- Você tem devê de casa? Pergunta difícil feita por Rafaela.

- De quem é a boneca? Uma pergunta fácil para Alícia e Érica.

- É difícil saber o nome do Dinossauro, nos disse Luiza.

É interessante dizer que, para algumas de nós, essa "dificuldade" era relativa aos nomes "complicados" dos dinossauros. Mas, ao ouvirmos a justificativa da criança percebemos o motivo que tornava essa pergunta uma pergunta difícil e, nos surpreendemos:

É difícil saber o nome do dinossauro porque tem muita letra!

Vinicius, então, nos diz sobre sua pergunta difícil:

- Se eu posso ficar na escola com a minha mãe.

Então, Zé Ricardo indagou:

- Por que a pergunta difícil é difícil?

Ninguém respondeu. Então, Cristiane, estudante, reformulou a pergunta:

- É diferente da fácil?

- Porque ela é difícil. Porque não é igual. É diferente! Porque tem pergunta fácil e difícil! Respondeu Pérola, pensativa.

O convite de voltarmos às perguntas em um outro momento finaliza esse nosso encontro entendendo que no movimento de exercitar o pensamento, não temos que acertar ou errar. Podemos errar ao acertarmos. Podemos acertar ao errarmos. As perguntas, como nos disse Pérola, são fáceis e difíceis e não fáceis ou difíceis.

Com as crianças, o convite para interrogarmos as clássicas dicotomias, que nos habitam, compreendidas como naturais e como "o modo" de organização do universo, na perspectiva de um pensamento metafísico ocidental: certo ou errado; saber ou não saber; cognição ou emoção; mente ou corpo; certeza ou incerteza; normal ou anormal; masculino ou feminino etc... Um modo de pensar que investe 
infâncias com as infâncias: narrativas de uma aproximação entre a filosofia e crianças de educação infantil

na disjunção e na simplificação e, sobretudo, na valorização do primeiro termo que despontencializa e submete a si próprio, o segundo.

Com as crianças, o desafio de pensar a complexidade constitutiva da vida nossa de cada dia, do estarmos juntos pensando, aprendendo e ensinando; experienciando processos de investigação educativa; movimentando nossas certezas mais profundas e basais. Processo que nos retira do estabelecido e nos lança em devir, nos abre à experiência que, se de fato se constituir como tal, nos transformará de tal maneira que não nos permitirá seguir da mesma forma.

Com as crianças percebemos que abrir-se para o acontecimento do encontro exige arriscar todo o tempo, criar e inventar, exercitar, no próprio encontro, o pensamento e, com esse processo, vivenciar outras possibilidades de relações com o outro e consigo mesmo.

A oportunidade de nos aproximarmos mais das crianças e de seus modos singulares de pensar, agir, ser e se colocar no mundo, foram interrogando modos aprendidos de compreender as crianças, suas infâncias e intensificando a ideia de uma infância potente, aguçando o pensamento acerca de algumas perguntas:

O que pode a infância das crianças?

O que pode resultar desta experiência de viver, com elas, a filosofia?

Que espaço têm as perguntas no dia a dia da sala de aula, nesta escola de educação infantil?

E, nesse processo, temos nos desafiado a sair do lugar do adulto educador/explicador e experimentar outras possibilidades de relação com as crianças. Vamos experienciando, como nos instiga Carlos Skliar na epígrafe deste texto, a estranhar, a viver o mistério do encontro, a tremer com o pensar, a viver a perplexidade e a perturbação com o ainda não sabido, o ainda não conhecido, com a possibilidade de sermos diferentes do que temos sido. Vamos exercitando, como nos provoca Rancière, com Jacotot, o mestre ignorante, a praticar a igualdade...

Não a igualdade como fim, como o paradigma moderno evidencia... A igualdade como princípio, como início das relações. 
A distância que a Escola e a sociedade pedagogizada pretendem reduzir é aquela de que vivem e que não cessam de reproduzir. Quem estabelece a igualdade como 'objetivo' a ser atingido, a partir da situação de desigualdade, de fato a posterga até o infinito. A igualdade jamais vem após como resultado a ser atingido. Ela deve sempre ser colocada antes. (RANCIÈRE, 2010, p. 11).

Aprendemos com Rancière/Jacotot que todos os sujeitos são igualmente inteligentes. Não cabe, nesta perspectiva, desigualdades ou hierarquizações mestres e aprendizes; explicador e explicados; conhecedores e não conhecedores; sabedores e não sabedores...

Esta perspectiva muda radicalmente nossas relações com os sujeitos da escola. Mais do que isso: expõe a impossibilidade de um sistema educacional levar à igualdade entre as pessoas, posto que se estrutura justamente na desigualdade de seus partícipes.

O que vamos percebendo nas experiências vividas com as crianças é justamente a potencialidade de construção de um espaço/tempo educativo que denuncia os limites dos modos como estamos pensando e fazendo escola ao mesmo tempo em que anuncia outros caminhos de uma escola ainda por se construir.

\section{Estaríamos propondo uma outra escola?}

Estaríamos resgatando seu sentido etimológico primeiro - Skholé como tempo livre?

Estaríamos investindo em uma escola que se apoie mais sobre Aión do que sobre Khronos para a estruturação de seu espaço/tempo?

Estaríamos investindo mais na importância da escola e os saberes que a atravessam do que em sua utilidade?

Não sabemos as respostas a estas questões. Aliás, não nos interessa muito chegar à solidez - e à solidão - destas respostas.

Nos lançamos com as crianças em um movimento de perguntas que se abrem a outras perguntas infinitamente, apostando na potência de uma infância que permite estar na escola, na vida, no mundo com as crianças, com as pessoas de modos outros. 
infâncias com as infâncias: narrativas de uma aproximação entre a filosofia e crianças de educação infantil

Nos lançamos com as crianças em temporalidades outras... tempos de sensibilidade e abertura; tempos de atenção e escuta; tempos de invenção e risco; tempos de interrogação e incertezas; tempos de encantamento e beleza; tempos de (des)aprender; tempos de duvidar; tempos de viver uma experiência de formação docente, quiçá, na perspectiva de uma formação como experiência.

\section{referências}

CONTRERAS, José; FERRÉ, Nuria Pérez de Lara. La experiencia y la investigación educativa. IN: CONTRERAS, José \& LARA, Nuria Pérez (Comps.) Investigar la experiencia educativa. Madrid: Ediciones Morata, 2010.

FREIRE, Paulo. Professora sim, tia não. Cartas a quem ousa ensinar. São Paulo: Cortez, 1995

KOHAN, Walter. Infância: entre a educação e a filosofia. Belo Horizonte: Autêntica, 2003. . Vida e Morte da Infância, entre o Humano e o Inumano. Educação \& Realidade, Porto Alegre, RS, v. 35, n. 3, p. 125-138, set/dez 2010.

Palavras, passos e nomes para um projeto. In: KOHAN, Walter; OLARIETA, Beatriz Fabiana (orgs.). Em Caxias, a filosofia en-caixa? A escola pública aposta no pensamento. Belo Horizonte: Autêntica, 2012. O mestre inventor. Relatos de um viajante educador. Belo Horizonte: Autêntica, 2013. Viajar para vivir: ensayar. La vida como escuela de viaje. Buenos Aires: Miño y Dávila editores, 2015.

KOHAN, Walter \& MASSCHELEIN, Jan. O pedagogo e/ou filósofo? Um exercício de pensar juntos. In: MASSCHELEIN, Jan; SIMONS, Maarten. A Pedagogia, a democracia, a escola. Belo Horizonte: Autêntica, 2014.

LARROSA, Jorge. Saber y educación. In: HOUSSAYE, Jean (org.). Educación y filosofía: enfoques contemporáneos. Buenos Aires: EUDEBA, 2003.

MATURANA, Humberto. A ontologia da realidade. Belo Horizonte: Editora UFMG, 1997.

RANCIÈRE, Jacques. O mestre ignorante: cinco lições sobre a emancipação intelectual. Trad. Lílian do Valle. Belo Horizonte: Autêntica, 2010.

RIBEIRO; T.; SAMPAIO; C. S.; SOUZA, R. Investigar narrativamente a formação docente: no encontro com o outro, experiências... Revista Roteiro, Joaçaba, v. 41, n. 1, jan./abr. 2016. SKLIAR, Carlos. Desobedecer a linguagem: educar. Belo Horizonte: Autêntica, 2014.

Recebido em: 27.10 .2016

Aceito em: 07.11.2016 